\title{
Disability related to COPD tool (DIRECT): towards an assessment of COPD-related disability in routine practice
}

This article was published in the following Dove Press journal:

International Journal of COPD

4 July 2011

Number of times this article has been viewed

\author{
B Aguilaniu' \\ J Gonzalez-Bermejo² \\ A Regnault ${ }^{3}$ \\ C Dias Barbosa ${ }^{3}$ \\ B Arnould ${ }^{3}$ \\ M Mueser ${ }^{4}$ \\ G Granet ${ }^{5}$ \\ M Bonnefoy ${ }^{6}$ \\ T Similowski ${ }^{2,7}$ \\ 'HYLAB, Physiologie Clinique, \\ Grenoble, France; ${ }^{2}$ Assistance \\ Publique - Hôpitaux de Paris, Groupe \\ Hospitalier Pitié-Salpêtrière, Service \\ de Pneumologie et Réanimation, Paris, \\ France; ' $M a p i$ Values, Lyon, France; \\ ${ }^{4}$ Formerly Boehringer Ingelheim, Paris, \\ France; ${ }^{5}$ General Practitioner, Sainte- \\ Foy-lès-Lyon, Paris, France; ${ }^{6}$ Centre \\ Hospitalier Lyon Sud, Lyon, France; \\ ${ }^{7}$ Université Paris 6 Pierre et Marie \\ Curie, ER I0, Paris, France
}

Correspondence: Antoine Regnault Mapi Values, 27 rue de la Villette, 69003 Lyon, France

Tel +33472I36662

Email antoine.regnault@mapivalues.com
Background: Chronic Obstructive Pulmonary Disease (COPD) is a worldwide public health concern. It is also a major source of disability that is often overlooked, depriving patients of effective treatments. This study describes the development and validation of a questionnaire specifically assessing COPD-related disability.

Methods: The DIsability RElated to COPD Tool (DIRECT) was developed according to reference methods, including literature review, patient and clinician interviews and test in a pilot study. A 12-item questionnaire was included for finalization and validation in an observational crosssectional study conducted by 60 French pulmonologists, who recruited 275 COPD patients of stage II, III and IV according to the GOLD classification. Rasch modeling was conducted and psychometric properties were assessed (internal consistency reliability; concurrent and clinical validity).

Results: The DIRECT score was built from the 10 items retained in the Rasch model. Their internal consistency reliability was excellent (Cronbach's alpha $=0.95)$. The score was highly correlated with the Saint George's Respiratory Questionnaire Activity score $(r=0.83)$ and the London Handicap Scale $(r=-0.70)$, a generic disability measure. It was highly statistically significantly associated to four clinical parameters $(P<0.001)$ : GOLD classification, BODE index, $\mathrm{FEV}_{1}$ and 6-minute walk distance.

Conclusion: DIRECT is a promising tool that could help enhance the management of COPD patients by integrating an evaluation of the COPD-related disability into daily practice.

Keywords: chronic obstructive pulmonary disease, daily medical practice, disability, disease management, questionnaires

\section{Background}

Chronic obstructive pulmonary disease (COPD) is a preventable and treatable disease with some significant extrapulmonary effects that may contribute to its severity in individual patients. Its pulmonary component is characterized by airflow limitation that is not fully reversible. The airflow limitation is usually progressive and associated with an abnormal inflammatory response of the lung to noxious particles or gases, the main source of which is tobacco smoking. COPD is a leading cause of morbidity and mortality worldwide, is burdensome to patients, physicians, and society, partially because the pleomorphic nature of COPD manifestations goes far beyond the loss of pulmonary function associated with the disease.

For patients, the main burden of COPD is the impact it has on their daily lives. ${ }^{1}$ Indeed, physical disability stemming from exercise-induced dyspnea, muscular deconditioning, and other factors has a major impact on the self-perceived quality of life of the patients. Yet quality of life in COPD can be improved by several therapeutic 
interventions, including the adequate use of bronchodilators ${ }^{2,3}$ and pulmonary rehabilitation. ${ }^{4}$

Primary care physicians (PCPs) are increasingly recognized as key to an optimal management of COPD. ${ }^{1,5}$ However, time is of the essence in routine medical practice and it is crucial for PCPs to have simple, practical decision-aid tools. Ideally, such tools should be responsive to educative and therapeutic interventions and therefore help practitioners and patients evaluate their effects.

Patient-reported instruments have been developed to investigate the impact of COPD on patients' lives. However, these instruments were either designed in a clinical research framework $^{6-9}$ or do not specifically assess disability. ${ }^{10-13}$

The objective of this study was to develop and validate a tool focusing specifically on COPD-related disability, appropriate for patients with a wide range of COPD severity.

\section{Materials and methods Development of the DIRECT questionnaire}

The development of the DIsability RElated to COPD Tool (DIRECT) (August 2005-June 2008) included the following steps: 1) A literature review collected disability-related concepts important to patients with COPD to develop the initial conceptual model of COPD-related disability; 2) Interviews with 3 PCPs eliciting general practitioners' expectations and experiences regarding the diagnosis and management of COPD validated the relevance of the disability-related concepts identified; 3) Interviews with 10 COPD patients enhanced understanding of patients' experiences of COPD and its impact on everyday life and collected patients' own words as a basis for item generation; 4) The conceptual model of COPD-related disability describing the overall concepts and sub-concepts of interest was created, and questionnaire items were generated; 5) Comprehension tests conducted with 5 COPD patients assessed the comprehension, relevance and acceptability of the tool's instructions, questions and response choices and allowed modification of potential flaws in the questionnaire.

The result of this process is a self-administered questionnaire composed of twelve items assessing disability in COPD patients. The initial comprehension tests showed that less than 5 minutes are needed to complete it. Overall concepts, detailed concepts and response scales are presented in Table 1.

Table I Concepts of interest identified during the development of DIRECT and corresponding items included in the questionnaire

General concepts
Basic Activities of Daily Living (BADL)

Instrumental Activities of Daily Living (IADL)

Advanced Activities of Daily Living (AADL)

Impact on daily life

\section{Items $^{\mathbf{a}}$}

Does it ever bother you to talk and discuss things? (4-point Likert-type response scale ranging from "never" to "all of the time")

Do you have trouble washing up or dressing? (4-point Likert-type response scale ranging from "never" to "all of the time")

Do you have trouble running small errands? (5-point Likert-type response scale ranging from "never" to "I am no longer able to do this" plus an additional response option "I am not the one who does the errands")

Do you ever have trouble doing housework or do-it-yourself projects in the house? (5-point Likert-type response scale ranging from "never" to "I am no longer able to do this" plus an additional response option "I do not do housework or do-it-yourself projects")

Do you ever have trouble going to places on foot? (5-point Likert-type response scale ranging from "never" to "I am no longer able to do this")

Do you ever have trouble climbing stairs? (5-point Likert-type response scale ranging from "never" to "I am no longer able to do this")

Do your breathing problems limit what you like to do during your daily life? (4-point Likert-type response scale ranging from "never" to "all of the time")

Do your breathing problems limit your relationships with others (in your daily life or at work)? (4-point Likert-type response scale ranging from "never" to "all of the time")

Do you have to rely on others to do certain tasks because of your breathing problems? (4-point Likert-type response scale ranging from "never" to "all of the time") Do you have to rest during the day because of your breathing problems? (4-point Likert-type response scale ranging from "never" to "all of the time")

Are you limited by your breathing problems in your sexual relationships? (5-point Likert-type response scale ranging from "never" to "I am no longer able to do this" plus an additional response option "I am not sexually active")

Are your breathing problems a disability for you during your everyday life? (4-point Likert-type response scale ranging from "never" to "all of the time") 
DIRECT was then included in a small cross-sectional multicenter, observational study conducted in France to test it under real life conditions. This pilot study included 10 PCPs and 5 pulmonologists who recruited 40 COPD patients with a cumulative tobacco-smoking in excess of 10 pack-years, a post-bronchodilator Forced Expiratory Volume in 1 second $\left(\mathrm{FEV}_{1}\right) /$ Forced Vital Capacity $(\mathrm{FVC})$ ratio $<0.7$ and a postbronchodilator $\mathrm{FEV}_{1}<80 \%$ predicted without exacerbation for at least 1 month before the study. The completion rate was excellent since no missing data were observed in the questionnaire and the participating physicians' feedback on the questionnaire was very good: all but one found the questionnaire useful and were considering using it in their daily practice.

\section{Validation study}

DIRECT was included for finalization and validation in an observational, multicenter, cross-sectional non-drug study conducted in 2009. One hundred French pulmonologists were asked to recruit 300 COPD patients with different stages of disease severity according to Global initiative for Obstructive Lung Disease (GOLD) classification 2008 (100 patients per stage II, III, and IV). ${ }^{14}$ The study was performed in accordance with good clinical practices and in compliance with local regulatory requirements. The appropriate national authorities and institutional review boards approved the protocol before study commencement. Each patient gave informed consent to participate. Eligible patients were those with a cumulative tobacco-smoking in excess of 10 pack-years, diagnosed with COPD with $\mathrm{FEV}_{1} / \mathrm{FVC}$ lower than 0.7 , without exacerbation for at least 6 weeks and without any other chronic lung disease or serious and disabling disease, subjectively considered to be "major" by the physician and likely to compromise the patient's participation in the study.

Investigators reported post-bronchodilator spirometric and blood gas measurements, 6-minute walk distance, COPD symptoms (sputum, cough), evaluation of physical and psychological disability and comorbidities listed in the Charlson comorbidity index (CCI). ${ }^{15}$ Patients completed 3 patient-reported instruments in addition to the DIRECT questionnaire: Saint George's Respiratory Questionnaire (SGRQ), ${ }^{16}$ London Handicap Scale (LHS) ${ }^{17}$ and Modified Medical Research Council (MMRC) Dyspnea scale. ${ }^{18}$ The SGRQ is frequently used to measure the impact of COPD and asthma on patient health status and provides three subdomain scores (Impact, Symptom and Activity) and one overall score. The LHS, a generic questionnaire evaluating patient's self-perceived disability, allows the calculation of an overall handicap severity score ranging from 0 (maximum possible disadvantage) to 100 (no disadvantage). The MMRC Dyspnea scale consists of 5 statements about perceived breathlessness, characterizing 5 dyspnea grades. A French version of this scale has been specifically developed for this study, using a process including forward and backward translations. ${ }^{19}$ The body-mass index, airflow obstruction, dyspnea, and exercise capacity (BODE) index, ${ }^{20}$ a composite measure of COPD severity ranging from 0 to 10 that integrates respiratory, perceptive and systemic aspects of COPD, was also computed.

\section{Linguistic validation of DIRECT into US English}

After finalization, a US English version of DIRECT was obtained by a linguistic validation process according to published standards ${ }^{21}$ including a conceptual analysis of the items, two independent forward translations from French to English, one backward translation, the review of the US English version by a clinician and its test with 5 COPD patients.

\section{Statistical analyses}

The finalization of DIRECT included item selection and score definition. Distribution of item responses and quality of completion was observed. It assumed that all items measured the same underlying unidimensional concept (disability due to COPD). A principal component analysis (PCA) was applied in which the total variance was expected to be predominantly explained by the first factor and all items were expected to strongly load on this factor.

Partial-Credit Models (PCM), ${ }^{22}$ a generalization of Rasch modeling, were applied to the DIRECT items to select those producing a model with good measurement properties. Rasch modeling assumes that items and individuals can be located on a common continuum, called latent trait, which corresponds to the unidimensional concept that is measured by the items. ${ }^{23}$ In this case, the latent trait was COPD-related disability. The response of a patient to a given item is modeled as a function of the respective locations of the item and the individual on the latent trait. Thus, items characterizing worse health status are likely to be endorsed only by patients with severe disease whilst items corresponding to better health status are likely to be endorsed by patients with mild health problems. While the Rasch model involves only dichotomous items, PCM allow items with ordinal response scales to be analyzed by focusing on "item thresholds": these are the values of the latent trait for which the most probable response to an item changes (for example, the value of the latent trait for which the response "a little" to a given item becomes more probable than the response "not at all"). 
An iterative approach was used to select items according to both the overall goodness-of-fit of the models by item-trait $\chi^{2}$ and individual item fit evaluated by $\chi^{2}$ values. ${ }^{24}$

The psychometric validation included assessment of concurrent and clinical validity and internal consistency reliability. ${ }^{25}$ Concurrent validity was measured by correlating the DIRECT score with SGRQ scores, LHS overall handicap severity scores and MMRC dyspnea scale using Spearman correlation coefficients. The DIRECT score was expected to have high correlations with measures of functional limitations (SGRQ Activity score and LHS overall score). For clinical validity, the associations of the DIRECT score with GOLD classification, physician subjective assessment of physical and psychological disability, BODE index, $\mathrm{FEV}_{1}$, 6-minute walk distance and CCI were observed. The association with the DIRECT score was investigated using ANOVA for ordinal variables and linear regression for continuous variables. The reliability coefficient of the DIRECT score (ratio of variance in true score to the variance in observed score) was estimated using Cronbach's coefficient alpha. Cronbach's alpha assesses internal consistency reliability and is calculated from the correlations among items included in a score and the number of items in the score.

The DIRECT score was described according to GOLD stages using cumulative distribution curves.

All analyses were performed using SAS statistical software version 9.2 (SAS Institute, Cary, NC, USA), except the Rasch modeling for which RUMM 2010 (RUMM Laboratory, Perth, Australia) was used. Results were considered statistically significant when the probability of a type I error was below $5 \%$.

\section{Results}

\section{Patient characteristics in the validation study}

Of the 100 pulmonologists who accepted to participate in the study, 60 recruited a total of 275 patients. Two hundred and forty seven of the corresponding questionnaires had no missing data. The majority of patients $(75.3 \%)$ were male. Mean age was 67 and 26.9\% were active smokers (Table 2). COPD severity distribution was well balanced, with $36.0 \%$ in stage II, 33.5\% in stage III and 30.5\% in stage IV according to GOLD classification 2008. Most patients coughed occasionally (46.9\%) or daily $(48.7 \%)$ and produced sputum (75.3\%). Overall, $61.5 \%$ of the patients had experienced an exacerbation in the previous year. On average, patients had one comorbid condition in addition to COPD (mean CCI of 1.9). The number of comorbidities increased with COPD severity (mean CCI of 1.6, 1.8 and 2.2 in GOLD II, III and IV patients respectively).

Forty-one point five percent of the patients were treated by the combination of $\beta 2$-agonists, glucocorticosteroids and long acting anticholinergics and $28 \%$ had home oxygen therapy (Table 3).

\section{DIRECT finalization}

All items had acceptable response distribution; no bimodal or skewed distribution was observed. The results of the finalization analyses are presented in Table 4. Most patients $(89.8 \%)$ answered all questionnaire items. The percentage of missing data per item ranged from $4.7 \%$ to $8.0 \%$, with item 11, concerning sexual activities, showing the highest percentage of missing data. The first factor of the principal component analysis explained $58.4 \%$ of the total variance of the 12 items of the questionnaire, supporting the unidimensionality hypothesis.

\section{Item selection and scoring algorithm}

Items 11 ("Impact on sex life") and 12 ("Handicap due to COPD") were eliminated from the calculation of the score because of their poor fit to the partial credit model. After reduction to a 10-item model, the overall fit of the model was very good (item-trait interaction $\chi^{2}=27.452 ; P=0.60$ ). Only item 1 ("Trouble talking") showed a significant $\chi^{2}$ value, indicating poor fit; however, because the overall fit was acceptable and this item potentially has great clinical value, it was retained. The distribution of item thresholds and patients on the latent trait (COPD-related disability) are presented in Figure 1. The DIRECT score was constituted by the unweighted sum of the responses to the 10 items retained in the partial credit model, yielding a score ranging between 0 and 34, with higher values indicating higher levels of disability.

\section{DIRECT validation}

\section{Concurrent validity}

The DIRECT score showed high correlation with the SGRQ Activity score (0.83) (Table 5). The correlations between the DIRECT score and the SGRQ Impact and Total scores were also very high ( 0.83 and 0.87 respectively). The DIRECT score was also highly correlated with the LHS overall handicap score and MMRC dyspnea scale $(-0.70$ and 0.73 respectively) and its correlation with the SGRQ Symptom score was lower than the correlations above, but was still fairly high (0.61). 
Table 2 Patient demographics and clinical characteristics in the overall population and according to GOLD stage

\begin{tabular}{|c|c|c|c|c|}
\hline & $\begin{array}{l}\text { Overall population } \\
(n=275)\end{array}$ & $\begin{array}{l}\text { GOLD stage II } \\
(n=99)\end{array}$ & $\begin{array}{l}\text { GOLD stage III } \\
(n=92)\end{array}$ & $\begin{array}{l}\text { GOLD stage IV } \\
(n=84)\end{array}$ \\
\hline \multicolumn{5}{|l|}{ Demographics and smoking } \\
\hline Age - mean (SD) & $67.1(10.7)$ & $66.7(11.3)$ & $66.9(10.8)$ & $67.7(9.8)$ \\
\hline Gender - male (\%) & 75.3 & 79.8 & 71.7 & 73.8 \\
\hline Smoking status - active smoker (\%) & 26.9 & 31.3 & 21.7 & 27.4 \\
\hline Number of pack-years - mean (SD) & 44.7 (19.9) & $42.1(16.4)$ & $42.3(20.0)$ & $50.3(22.3)$ \\
\hline \multicolumn{5}{|l|}{ Spirometric measurement } \\
\hline \multicolumn{5}{|l|}{ FEV } \\
\hline $\mathrm{N}$ & 275 & 99 & 92 & 84 \\
\hline Mean \% predicted (SD) & $44.7(14.8)$ & $61.1(7.9)$ & $40.7(5.7)$ & $29.8(7.4)$ \\
\hline \multicolumn{5}{|l|}{ FVC } \\
\hline $\mathrm{N}$ & 272 & 98 & 91 & 83 \\
\hline Mean \% predicted (SD) & $65.9(17.9)$ & $78.0(\mid 3.2)$ & $64.0(14.6)$ & $53.6(17.0)$ \\
\hline \multicolumn{5}{|l|}{ SVC } \\
\hline $\mathrm{N}$ & 241 & 88 & 80 & 73 \\
\hline Mean \% predicted (SD) & $69.5(18.8)$ & $80.1(14.8)$ & $67.8(17.4)$ & $58.5(17.6)$ \\
\hline \multicolumn{5}{|l|}{ IC } \\
\hline $\mathrm{N}$ & 162 & 54 & 52 & 56 \\
\hline Mean \% predicted (SD) & $65.9(24.7)$ & $78.1(24.4)$ & $61.0(22.9)$ & $58.7(22.6)$ \\
\hline \multicolumn{5}{|l|}{ RV } \\
\hline $\mathrm{N}$ & 259 & 93 & 86 & 80 \\
\hline Mean \% predicted (SD) & $174.8(67.6)$ & I55.4 (48.4) & $173.7(69.8)$ & $198.4(77.1)$ \\
\hline \multicolumn{5}{|l|}{ FRC } \\
\hline $\mathrm{N}$ & 165 & 63 & 51 & 51 \\
\hline Mean \% predicted (SD) & I38.0 (44.I) & I25.5 (34.6) & 137.7 (39.9) & I53.7 (53.4) \\
\hline \multicolumn{5}{|l|}{ TLC } \\
\hline $\mathrm{N}$ & 266 & 96 & 88 & 82 \\
\hline Mean \% predicted (SD) & II $0.5(28.5)$ & $106.4(23.7)$ & $109.9(28.7)$ & $116.0(32.5)$ \\
\hline \multicolumn{5}{|l|}{ Arterial blood gases } \\
\hline \multicolumn{5}{|l|}{$\mathrm{PaO}_{2}$} \\
\hline $\mathrm{N}^{2}$ & 228 & 77 & 75 & 76 \\
\hline Mean mmHg (SD) & $68.1(12.0)$ & $74.9(10.2)$ & $70.7(9.2)$ & $58.6(10.0)$ \\
\hline \multicolumn{5}{|l|}{$\mathrm{PaCO}_{2}$} \\
\hline $\mathrm{N}^{2}$ & 227 & 76 & 75 & 76 \\
\hline Mean mmHg (SD) & $40.4(5.2)$ & $38.6(4.2)$ & $39.9(4.7)$ & $42.6(5.7)$ \\
\hline \multicolumn{5}{|l|}{ Symptoms and comorbidities } \\
\hline \multicolumn{5}{|l|}{ 6-minute walk distance } \\
\hline $\mathrm{N}$ & 275 & 99 & 92 & 84 \\
\hline Mean \% of predicted value (SD) & $69.3(28.0)$ & $82.0(23.0)$ & $73.5(28.1)$ & $49.5(22.3)$ \\
\hline \multicolumn{5}{|l|}{ Chronic cough - \% } \\
\hline Never & 4.0 & 4.0 & 3.3 & 4.8 \\
\hline Occasionally & 46.9 & 55.6 & 50.0 & 33.3 \\
\hline Daily & 48.7 & 40.4 & 45.7 & 61.9 \\
\hline Sputum production - \% & 75.3 & 78.8 & 68.5 & 78.6 \\
\hline Exacerbation in the past 12 months - \% & 61.5 & 49.5 & 59.8 & 77.4 \\
\hline \multicolumn{5}{|l|}{$\mathrm{CCl}$} \\
\hline $\mathrm{N}$ & 275 & 99 & 92 & 84 \\
\hline Mean (SD) & $1.9(1.1)$ & $1.6(0.9)$ & $1.8(1.1)$ & $2.2(1.2)$ \\
\hline \multicolumn{5}{|l|}{ BODE index } \\
\hline $\mathrm{N}$ & 250 & 91 & 84 & 75 \\
\hline Mean score (SD) & $4.1(2.5)$ & $2.0(1.5)$ & $4.3(1.8)$ & $6.4(1.7)$ \\
\hline
\end{tabular}

Abbreviations: FEV , post-bronchodilator Forced expiratory volume in one second; post-bronchodilator FVC, Forced Vital Capacity; SVC, Slow Vital Capacity; IC, Inspiratory Capacity; RV, Residual Volume; FRC, Functional Residual Capacity; TLC, Total Lung Capacity.

\section{Clinical validity}

The difference in the mean DIRECT score was statistically significant in groups defined according to GOLD stages $(P<0.001)$, physician subjective assessment of physical disability $(P<0.001)$, and physician assessment of psychological disability $(P<0.001)$ (Table 6). Significant relationships were observed in univariate linear regressions linking the DIRECT score and the BODE index $\left(P<0.001 ; \mathrm{R}^{2}=0.47\right)$, post-bronchodilator FEV $_{1}\left(P<0.001 ; \mathrm{R}^{2}=0.25\right), 6$-minute walk 
Table 3 Management of COPD in the overall population and according to GOLD stage

\begin{tabular}{|c|c|c|c|c|}
\hline & $\begin{array}{l}\text { Overall population } \\
(n=275)\end{array}$ & $\begin{array}{l}\text { GOLD stage II } \\
(n=99)\end{array}$ & $\begin{array}{l}\text { GOLD stage III } \\
(n=92)\end{array}$ & $\begin{array}{l}\text { GOLD stage IV } \\
(n=84)\end{array}$ \\
\hline \multicolumn{5}{|l|}{ Drug treatment - \% } \\
\hline Short acting $\beta 2$-agonist or anticholinergics & 2.9 & 6.1 & 1.1 & 1.2 \\
\hline $\begin{array}{l}\text { Short acting and long acting } \beta 2 \text {-agonist or } \\
\text { anticholinergics - no glucocorticosteroids }\end{array}$ & 9.5 & 16.2 & 6.5 & 4.8 \\
\hline$\beta 2$-agonists + glucocorticosteroids & 17.1 & 12.1 & 20.7 & 19.0 \\
\hline $\begin{array}{l}\beta 2 \text {-agonists }+ \text { glucocorticosteroids + long } \\
\text { acting anticholinergics }\end{array}$ & 41.5 & 26.3 & $5 \mathrm{I} . \mathrm{I}$ & 48.8 \\
\hline Other $^{a}$ & 26.9 & 33.3 & 20.7 & 26.2 \\
\hline Home oxygen therapy - \% & 28.0 & 15.2 & 19.6 & 52.4 \\
\hline Pulmonary rehabilitation - $\%$ & 22.2 & 12.1 & 25.0 & 31.0 \\
\hline Regular respiratory exercise - \% & 28.0 & 19.2 & 27.2 & 39.3 \\
\hline
\end{tabular}

Note: ${ }^{a}$ Other includes other combinations of treatments as well as other treatment such as methylxanthine.

distance $\left(P<0.001 ; \mathrm{R}^{2}=0.21\right)$ and CCI $(P<0.001 ;$ $\left.\mathrm{R}^{2}=0.05\right)$.

\section{Internal consistency reliability}

Cronbach's alpha coefficient calculated for the 10-item score was very high at 0.947 , indicating excellent internal consistency reliability.

\section{Description of DIRECT score}

The cumulative distributions of the DIRECT score according to GOLD stage are given in Figure 2.

The following mean (SD) DIRECT scores were also calculated: 12.1 (7.7) in smokers, 15.3 (8.3) in ex-smokers $(P<0.01) ; 16.2(8.0)$ in patients who had an exacerbation in the previous 12 months, $11.6(7.6)$ in those who had not $(P<0.001) ; 21.0(6.7)$ in patients with home oxygen therapy, 11.9 (7.3) in patients without $(P<0.001)$; 17.7 (8.2) in patients who participated in rehabilitation programs, 13.4 (7.9) in patients who did not $(P<0.001)$.

\section{Discussion}

At the end of a development and validation process adhering to reference methods, ${ }^{26,27}$ the 10 -item, self-administered, "Disability RElated to COPD Tool” (DIRECT) appears to have very good measurement properties. Item generation encompassed both the clinical judgment of practitioners and opinions of patients in terms of content and wording. It was well accepted by patients and physicians during

Table 4 Finalization of the DIRECT questionnaire: Quality of completion and principal component analysis loadings on the first factor of the items and final partial-credit model results

\begin{tabular}{|c|c|c|c|c|c|c|c|c|}
\hline \multirow[t]{3}{*}{ DIRECT item content } & \multirow{3}{*}{$\begin{array}{l}\text { Percentage } \\
\text { of missing } \\
\text { data } \\
(n=275)\end{array}$} & \multirow{3}{*}{$\begin{array}{l}\text { PCA first } \\
\text { factor } \\
\text { loading } \\
(n=247)\end{array}$} & \multicolumn{6}{|c|}{ Final $(10$-item) partial-credit model results $(n=247)$} \\
\hline & & & \multicolumn{2}{|c|}{ Item goodness of fit } & \multicolumn{4}{|c|}{ Item thresholds ${ }^{b}$} \\
\hline & & & $\chi^{2}$ & $P$-value ${ }^{a}$ & lst & 2nd & 3 rd & 4th \\
\hline I. Trouble talking & 5.5 & 0.70 & 10.20 & $<0.001$ & -2.6 & 0.4 & 2.2 & - \\
\hline $\begin{array}{l}\text { 2. Trouble washing or } \\
\text { getting dressed }\end{array}$ & 4.7 & 0.77 & 3.05 & 0.37 & -1.8 & 0.4 & 1.3 & - \\
\hline 3. Trouble doing shopping & 5.1 & 0.65 & 1.99 & 0.56 & -2.9 & -0.2 & 1.0 & 2.1 \\
\hline 4. Trouble doing housework & 5.5 & 0.60 & 1.49 & 0.68 & -3.6 & -0.2 & 1.4 & 2.4 \\
\hline 5. Trouble walking & 4.7 & 0.87 & 3.81 & 0.26 & -4.5 & -0.8 & 0.7 & 4.7 \\
\hline 6. Trouble climbing stairs & 4.7 & 0.78 & 4.65 & 0.17 & -4.6 & -0.9 & 0.5 & 4.9 \\
\hline 7. Impact on every day life & 5.1 & 0.87 & 2.80 & 0.41 & -3.3 & 0.5 & 2.8 & - \\
\hline 8. Impact on social life & 5.1 & 0.81 & 1.04 & 0.79 & -2.4 & 0.2 & 2.2 & - \\
\hline 9. Rely upon others & 5.5 & 0.83 & 0.45 & 0.93 & -3.0 & 0.3 & 2.7 & - \\
\hline $\begin{array}{l}\text { 10. Taking rest during } \\
\text { the day }\end{array}$ & 5.1 & 0.82 & 1.22 & 0.74 & -2.9 & -0.1 & 3.0 & - \\
\hline II. Impact on sex life & 8.0 & 0.48 & - & - & - & - & - & - \\
\hline 12. Handicap due to COPD & 4.7 & 0.89 & - & - & - & - & - & - \\
\hline
\end{tabular}

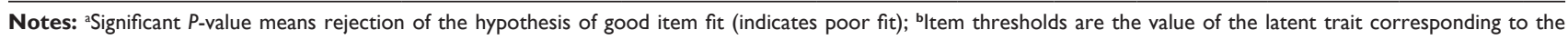
boundaries between adjacent response categories. For example, the first threshold indicates the value of the latent trait below which the most probable response is the first response option and above which the most probable response is the second response option. 

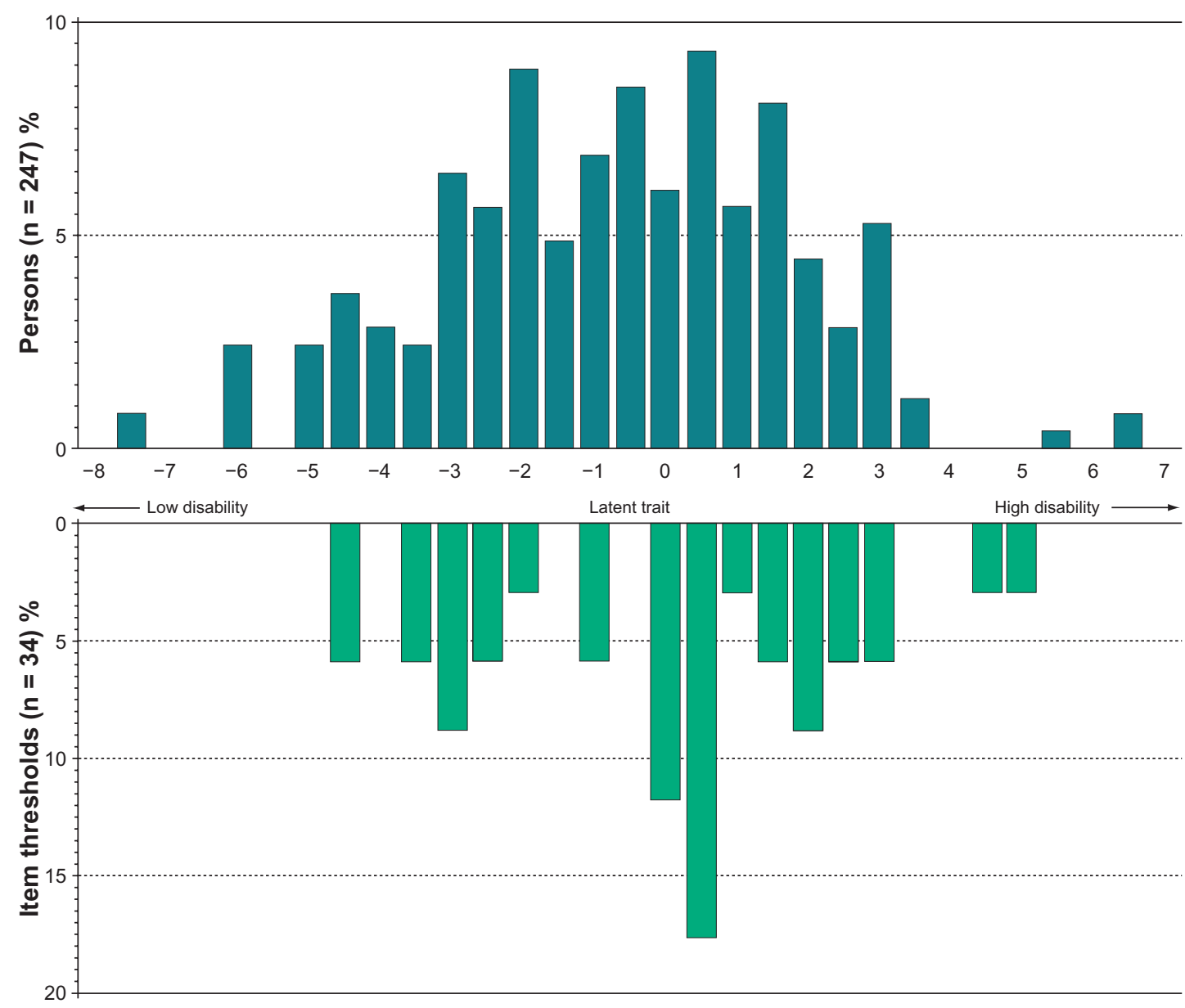

Figure I Rasch analysis - Distribution of patients and item thresholds on the latent trait $(n=247)$.

This figure allows patients and item thresholds (ie, value corresponding to the boundaries between adjacent response categories) to be represented on the same scale, the latent trait (X-axis): the distribution of patients is plotted in the top part of the figure; the distribution of thresholds is plotted in the bottom part. In this instance, the latent trait (X-axis) represents the disability. The range of disability levels of included patients was wide but the items of the questionnaire covered this wide range of disability levels fairly well.

the test phase and the pilot study, as well as during the validation study. All possible score values were observed in the study population, and the score did not exhibit floor or ceiling effects; this indicates adequate coverage of the measured concept, namely the extent of COPD-related disability.
In line with the approach underpinning the international classification of functioning, disability and health (ICF) promoted by the World Health Organization (WHO), ${ }^{28}$ the questionnaire focuses on disability and functioning as an interaction between health condition (ie, COPD and respiratory problems, in this specific case) and contextual factors.

Table 5 Concurrent validity of the DIRECT score: Spearman correlation coefficients between patient-reported outcomes scores $(n=247)$

\begin{tabular}{|c|c|c|c|c|c|c|}
\hline & $\begin{array}{l}\text { DIRECT } \\
\text { score }\end{array}$ & $\begin{array}{l}\text { SGRQ symptom } \\
\text { score }\end{array}$ & $\begin{array}{l}\text { SGRQ activity } \\
\text { score }\end{array}$ & $\begin{array}{l}\text { SGRQ impact } \\
\text { score }\end{array}$ & $\begin{array}{l}\text { SGRQ total } \\
\text { score }\end{array}$ & $\begin{array}{l}\text { LHS overall handicap } \\
\text { severity score }\end{array}$ \\
\hline SGRQ symptom score & 0.61 & & & & & \\
\hline SGRQ activity score & 0.83 & 0.56 & & & & \\
\hline SGRQ impact score & 0.83 & 0.72 & 0.78 & & & \\
\hline SGRQ total score & 0.87 & 0.78 & 0.87 & 0.97 & & \\
\hline $\begin{array}{l}\text { LHS overall handicap } \\
\text { severity score }\end{array}$ & -0.70 & -0.45 & -0.70 & -0.65 & -0.70 & \\
\hline MMRC dyspnea scale & 0.73 & 0.48 & 0.70 & 0.70 & 0.72 & -0.67 \\
\hline
\end{tabular}

Abbreviations: LHS, London Handicap Scale; MMRC, Modified Medical Research Council; SGRQ, St Georges Respiratory Questionnaire. 
Table 6 Clinical validity of DIRECT score $(n=247)$

\begin{tabular}{|c|c|c|c|c|}
\hline & \multirow[t]{2}{*}{$\mathbf{N}$} & \multicolumn{2}{|c|}{ DIRECT score } & \multirow[t]{2}{*}{$P$-value } \\
\hline & & Mean & SD & \\
\hline \multicolumn{5}{|c|}{ COPD severity according to GOLD classification } \\
\hline GOLD stage II & 93 & 9.9 & 6.8 & \multirow[t]{3}{*}{$<0.001$} \\
\hline GOLD stage III & 84 & 14.7 & 7.5 & \\
\hline GOLD stage IV & 70 & 20.0 & 7.2 & \\
\hline \multicolumn{5}{|c|}{ Physician assessment of physical handicap } \\
\hline Not at all & 3 & 3.7 & 3.5 & \multirow[t]{5}{*}{$<0.001$} \\
\hline A little & 36 & 5.7 & 5.2 & \\
\hline Moderately & 94 & 12.0 & 6.6 & \\
\hline A lot & 91 & 18.3 & 6.7 & \\
\hline Enormously & 21 & 24.1 & 5.5 & \\
\hline \multicolumn{5}{|c|}{ Physician assessment of psychological handicap } \\
\hline Not at all & 24 & 6.9 & 5.8 & \multirow[t]{5}{*}{$<0.001$} \\
\hline A little & 91 & 12.0 & 7.8 & \\
\hline Moderately & 72 & I5. I & 7.6 & \\
\hline A lot & 49 & 19.7 & 6.0 & \\
\hline Enormously & 9 & 23.1 & 9.3 & \\
\hline
\end{tabular}

Note: aNOVA $P$-value for between-group comparisons.

It covers activities of daily living potentially impacted by COPD to various degrees (dressing/washing oneself; shopping; cleaning/doing handwork at home; walking; climbing stairs; talking) and more global aspects, but still related to disability, like self-perceived general impact on everyday life, impact on social life, and impact on interactions with others. Though the items about sex life and overall handicap due to COPD were removed from the score because they weakened the overall fit of the partial-credit models, they were kept in the questionnaire, at least provisionally. The "impact on sex life" item was retained in order to prompt discussions between physicians and patients on this sensitive topic. Ninety-two percent of the patients did answer this question, which suggest that this does represent a relevant issue. Among the patients who declared themselves sexually active, about $80 \%$ mentioned suffering from respiratory-related limitations in this area of their life. This is consistent with COPD having a negative impact on sexual activity, a notion that is intuitive but has not been the object of extensive attention to date. ${ }^{29}$ The item about the overall handicap due to breathing difficulties was retained as it may be a good candidate for an extremely rapid assessment summarizing all the aspects covered by the questionnaire, without having to calculate any score. Indeed, as it is positioned at the end of the questionnaire, from a cognitive perspective, it can be assumed that the response of the patient will be reflecting the various aspects addressed in the questionnaire. The relevance of keeping these two items in the questionnaire should be tested further in future studies.

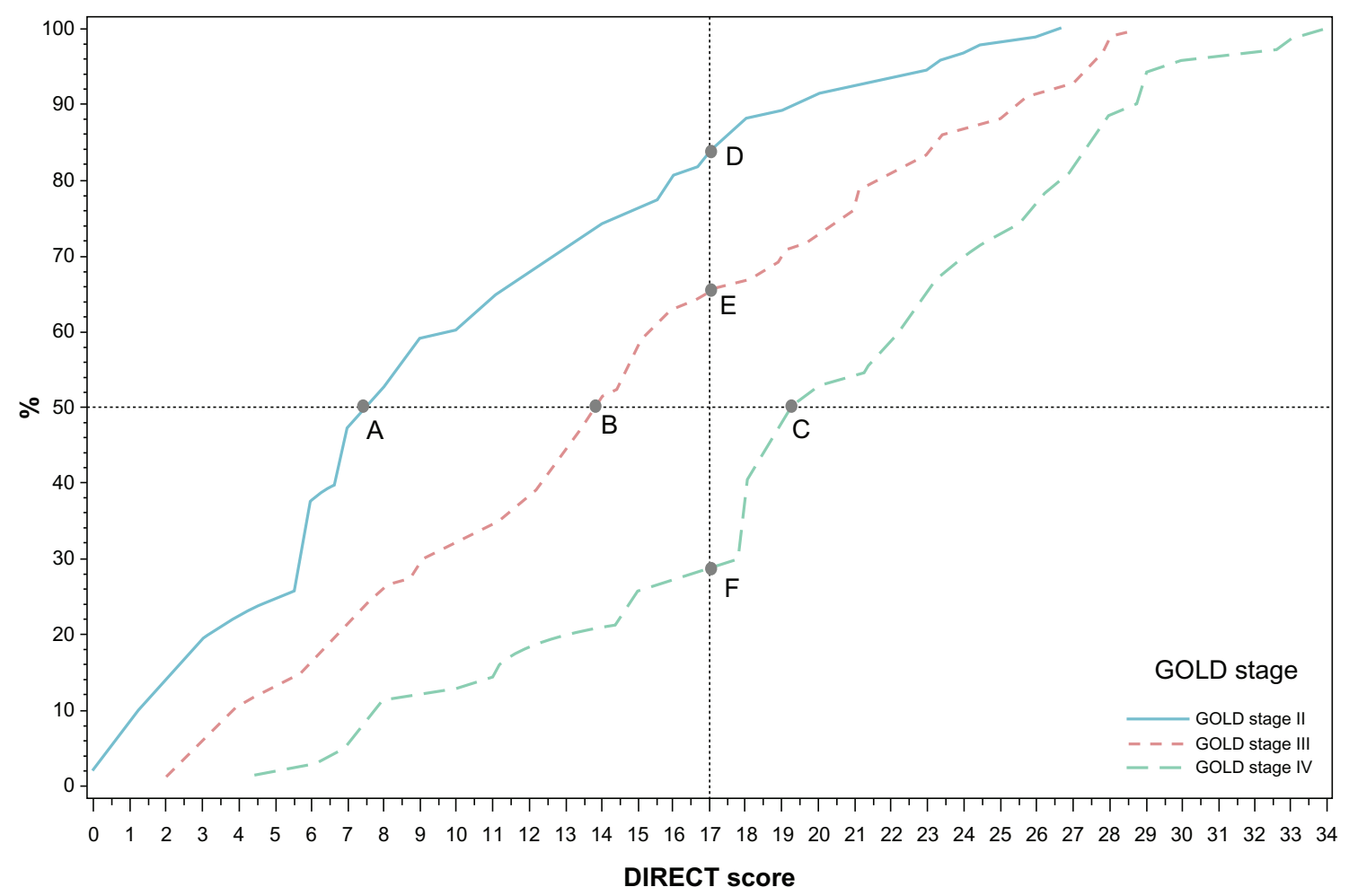

Figure 2 Cumulative distribution curves of the DIRECT score according to GOLD stage $(n=247)$.

Note: Cumulative distribution curves display the percentage of patients (Y-axis) having at least a given score (X-axis). Half of GOLD stage II patients had DIRECT scores below 7 (point A), half of GOLD stage III patients had DIRECT scores lower than 14 (point B) and half of GOLD stage IV patients had DIRECT scores lower than I9 (point C). This graph also shows the percentage of patients in each group who had a DIRECT score lower than I7, the mid-point of the scale: this was $85 \%$ in GOLD stage II (point D), 65\% in GOLD stage III (point E), and only about $30 \%$ in GOLD stage IV. 
The 10-item score had an excellent fit to a partial-credit model, supporting its interval scaling properties. It also exhibited very high internal consistency reliability. The reliability of a measurement instrument closely depends on measurement error. If measurement error is too great, it becomes unreasonable to use a questionnaire for individual decisions. Conversely, reliability coefficient values as high as 0.95 , like those reached by DIRECT in this study, allow decisions to be made at the individual level. ${ }^{30}$ In addition, DIRECT was closely correlated with variables indicative of the severity of COPD and its ability to discriminate between patient groups was excellent. Thus, it is reasonable to expect DIRECT to be useful at the individual level.

The DIRECT score was closely correlated to wellestablished patient-reported outcomes instruments. Excellent correlations were found not only with respiratoryspecific questionnaires such as the SGRQ and the MMRC scale, but also with the results of a generic measure of handicap, the LHS. This indicates that despite the brevity of the questionnaire, the score is a valid measure of COPDrelated disability. The DIRECT score was also significantly associated with comorbidities as measured by the CCI, even though the strength of this association was marginal (only $5 \%$ of the DIRECT score variance was explained by the $\mathrm{CCI})$. This indicates that while DIRECT mainly captures COPD-related disability, it does not completely disregard the potential impact on daily living of the frequent comorbid conditions.

In interpreting the results of this observational study, it is important to consider the nature of the population under scrutiny. Although the overall population was well balanced regarding GOLD stages, it might be slightly different than "standard" COPD populations. Indeed, resting hyperinflation seemed highly prevalent, with a mean functional residual capacity (FRC) of $125 \%$ predicted and a mean inspiratory capacity (IC) of $65 \%$ predicted in the GOLD stage II patients. This might be considered surprising, as GOLD stage II patients often have normal FRC and IC/TLS ratios, see for example Albuquerque et al. ${ }^{31}$ Yet hyperinflation is a major determinant of COPD-related impairment in activities of daily living. ${ }^{32}$ Possibly in line with this, the proportion of patients receiving triple therapy with long-acting beta-agonists, inhaled corticosteroids, and a long acting anticholinergic was high $(41.5 \%$ of the overall population). More than $50 \%$ of GOLD stage IV patients received home oxygen, which might also indicate a selection bias toward a severe population. However, even though these specific features of the study population could alter the estimation of the level of disability due to COPD, they do not have a major impact on the primary objective of the study, ie, the assessment of DIRECT's psychometric properties.

Other patient-completed questionnaires that could be used in daily medical practice to help with COPD patient management have been proposed in recent years: the COPD Assessment test (CAT) ${ }_{11}^{11}$ the clinical COPD questionnaire (CCQ), ${ }^{12,13}$ or the visual simplified respiratory questionnaire (VSRQ).${ }^{10}$ These instruments cover various aspects of the health status of COPD patients (symptoms, energy, sleep, etc.) and can help physicians get a better global picture. But, as illustrated on Figure 3, focusing on disability can be instrumental to certain therapeutic decisions, like the prescription of long-acting bronchodilators or the initiation of a rehabilitation program. In addition, monitoring the impact of therapeutic interventions on disability makes a lot of sense

\section{Available tools}
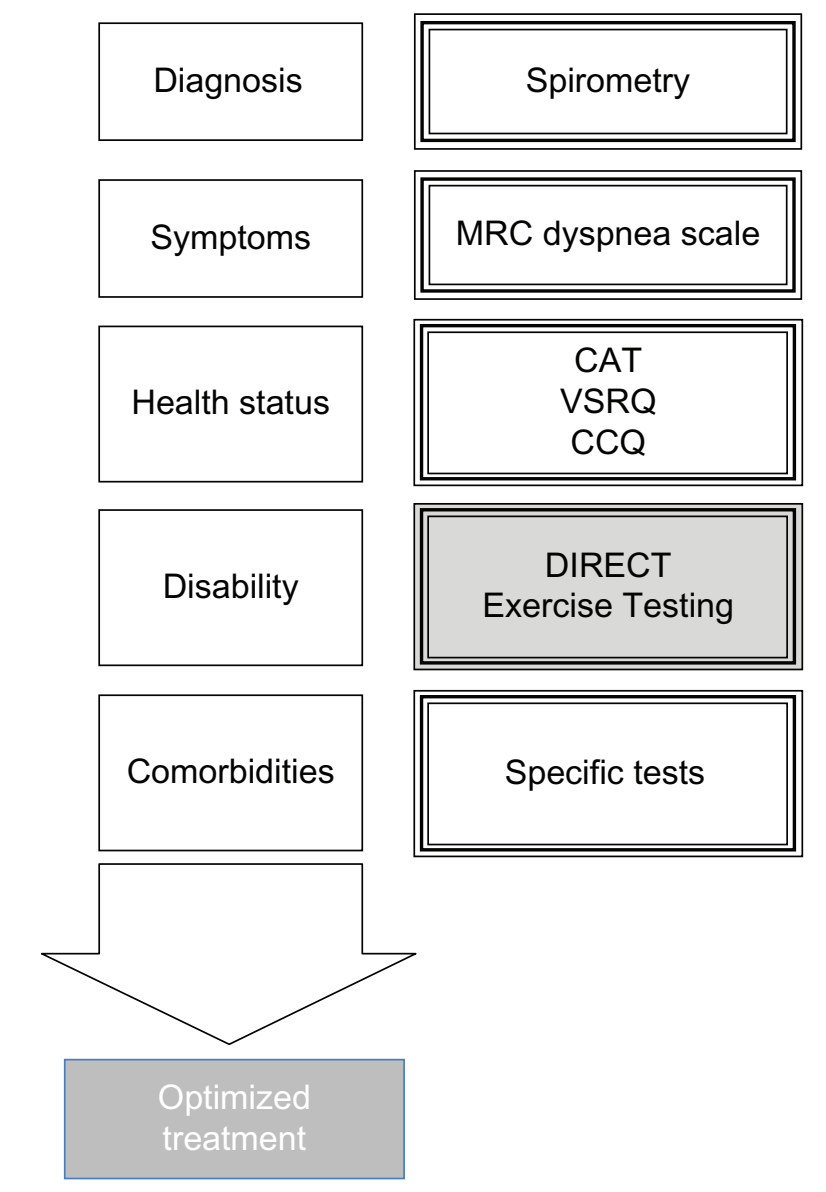

Figure 3 Schematic representation of COPD patient management with tools available to physicians.

Abbreviations: MRC, Medical Research Council; CAT, COPD Assessment Test; CCQ, Clinical COPD Questionnaire; VSRQ, Visual Simplified Respiratory Questionnaire; DIRECT, DIsability RElated to COPD Tool. 
from a clinical perspective. For these reasons and because the impact of COPD on activities of daily living is critical to the patients, ${ }^{1}$ a specific measure of COPD-related disability should usefully complement the currently available patientreported evaluation tools.

With this in mind, DIRECT was devised to help PCPs recognize COPD-related disability, for them to integrate this dimension of the disease and take it into account in their management strategy. The whole development process was customized to this objective. Intended for use in a primary care setting, DIRECT was purposely short and easily administered, with a score that can be calculated by hand without any kind of weighting. Of note, DIRECT is not a COPD diagnosis tool. It is intended to become one of the instruments that are available to holistically describe a COPD patient (like, for example, exercise testing or nutritional assessment) and support therapeutic decisions by providing a standardized assessment. It could also, if proven responsive to interventions, be used to monitor the efficacy of these therapeutic decisions. Several options can be envisioned for the use of DIRECT in routine practice.

Firstly, DIRECT could be used to support patient-clinician communication about COPD-related disability. Indeed, the goals and expectations of the patients and their physicians do not always coincide during a consultation. ${ }^{33}$ Discussing the principles of disease management and agreeing upon them optimizes the chances of success. ${ }^{34}$ Any tool likely to facilitate this exchange is therefore worth consideration. In this respect, DIRECT can be useful because it provides additional information on a specific, concrete aspect of COPD that is highly relevant to patients, even though it is seldom brought forward spontaneously.

Secondly, DIRECT could be used by PCPs as a decision aid when disability should be considered (eg, initiation of long-acting bronchodilators, or pulmonary rehabilitation). DIRECT has been shown to be a valid and reliable measure of COPD-related disability but interpretation guides should be given to support COPD management decisions. The available results (namely the PCM results, the cumulative distribution curve, or the distribution of DIRECT scores in various subgroups) can provide raw interpretation rules. Indeed, it could be hypothesized that a DIRECT score greater than 10 indicates a noticeable disability and that a DIRECT score above 20 indicates high levels of disability. Nonetheless, further research is needed to refine these reference values and optimize decision rules from DIRECT.

Thirdly, DIRECT could help monitor the efficacy of therapeutic strategies by assessing their impact on disability.
This will imply studies of its responsiveness to interventions aimed at improving COPD-related disability and known to improve quality of life at population (eg, the pulmonary rehabilitation-related improvement in the SGRQ) ${ }^{35}$ and individual level.

\section{Conclusion}

To conclude, we submit that DIRECT is a promising instrument for the identification of COPD-related disability in routine practice. Some work remains to be done before DIRECT is used for daily management of COPD patients. Some evidence on its responsiveness to interventions and practical decision rules to make its score more operational would be of great value in this purpose. Additional language versions of the questionnaire, cautiously taking into account the possible interference of cultural issues, would also allow its use in international settings. Nonetheless, we are confident that its focused nature will foster physician/patient discussions and expose more patients to interventions that improve their capacity to perform daily activities.

\section{List of abbreviations}

BODE, Body-mass index, airflow Obstruction, Dyspnea, and Exercise capacity; CAT, COPD Assessment Test; CCI, Charlson Comorbidity Index; CCQ, Clinical COPD Questionnaire; COPD, Chronic Obstructive Pulmonary Disease; DIRECT, DIsability RElated to COPD Tool; FVC, Forced Vital Capacity; $\mathrm{FEV}_{1}$, Forced expiratory volume in one second; FRC, Functional Residual Capacity; GOLD, Global initiative for chronic Obstructive Lung Disease; IC, Inspiratory Capacity; ICF, International Classification of Functioning, Disability and Health; LHS, London Handicap Scale; MMRC, Modified Medical Research Council; PCA, Principal Component Analysis; PCP, Primary Care Practitioner; PCM, PartialCredit Model; RV, Residual Volume; SD, Standard Deviation; SGRQ, St Georges Respiratory Questionnaire; SVC, Slow Vital Capacity; TLC, Total Lung Capacity; WHO, World Health Organization.

\section{Authors' contributions}

BAg, JGB, MB, GG, and TS provided clinical and scientific expertise on COPD throughout the project, in particular for identification of clinical research questions; definition of objectives; finalization of the questionnaire; and pilot and validation study designs. They also critically reviewed the manuscript. BAg, JGB and TS also participated in the interpretation of results. AR participated in the validation study design; designed and performed statistical analyses; 
participated in the interpretation of results; and drafted the manuscript. CDB managed the global organization of the project; managed the validation study; participated in the linguistic validation to US English; and critically reviewed the manuscript. BAr provided scientific expertise on: the methodology used to develop the questionnaire; the pilot and validation study designs and the statistical analyses; participated in the item development of the questionnaire and in the interpretation of the study results; and critically reviewed the manuscript. MM steered the pilot and validation studies; participated in the interpretation of results; and critically reviewed the manuscript. All approved the final version of the manuscript.

\section{Acknowledgments}

Aude Roborel de Climens (Mapi Values) managed the pilot study and Nadia Fabre (Mapi Values) provided support with the fieldwork for the validation study.

We thank François Denis (Boehringer Ingelheim France) for his support in finalizing this article.

\section{Disclosure}

Financial support for this study was provided by an unrestricted grant from Boehringer Ingelheim France. MM was employed by Boehringer Ingelheim France at the time of the study. AR, CDB and BAr are paid consultants to the sponsor. $\mathrm{BAg}, \mathrm{JGB}, \mathrm{GG}, \mathrm{MB}$ and TS are paid experts to the sponsor.

\section{Copyrights}

The DIsability RElated to COPD Tool (DIRECT) is protected by copyright with all rights reserved to Pfizer and Boehringer Ingelheim. Do not use without permission. For permission to use DIRECT, please contact Boehringer Ingelheim France (francois.denis@boehringer-ingelheim.com).

\section{References}

1. Rodriguez Gonzalez-Moro JM, de Lucas RP, Izquierdo Alonso JL, et al. Impact of COPD severity on physical disability and daily living activities: EDIP-EPOC I and EDIP-EPOC II studies. Int $J$ Clin Pract. 2009;63(5):742-750.

2. Appleton S, Poole P, Smith B, Veale A, Lasserson TJ, Chan MM. Long-acting beta2-agonists for poorly reversible chronic obstructive pulmonary disease. Cochrane Database Syst Rev. 2006;3:CD001104.

3. Barr RG, Bourbeau J, Camargo CA, Ram FS. Tiotropium for stable chronic obstructive pulmonary disease: a meta-analysis. Thorax. 2006; 61(10):854-862.

4. Lacasse Y, Martin S, Lasserson TJ, Goldstein RS. Meta-analysis of respiratory rehabilitation in chronic obstructive pulmonary disease. A Cochrane systematic review. Eura Medicophys. 2007;43(4): 475-485.

5. Price D, Freeman D, Cleland J, Kaplan A, Cerasoli F. Earlier diagnosis and earlier treatment of COPD in primary care. Prim Care Respir J. 2011;20(1):15-22.
6. Alvarez-Gutierrez FJ, Miravitlles M, Calle M, Gobartt E, Lopez F, Martin A. Impact of chronic obstructive pulmonary disease on activities of daily living: results of the multicenter EIME study. Arch Bronchoneumol. 2007;43(2):64-72.

7. Garrod R, Bestall JC, Paul EA, Wedzicha JA, Jones PW. Development and validation of a standardized measure of activity of daily living in patients with severe COPD: the London Chest Activity of Daily Living scale (LCADL). Respir Med. 2000;94(6):589-596.

8. Yoza Y, Ariyoshi K, Honda S, Taniguchi H, Senjyu H. Development of an activity of daily living scale for patients with COPD: the Activity of Daily Living Dyspnoea scale. Respirology. 2009;14(3):429-435.

9. Kuhl K, Schurmann W, Rief W. COPD-Disability-Index (CDI) - ein neues Verfahren zur Erfassung der COPD-bedingten Beeinträchtigun. COPD disability index (CDI) - a new instrument to assess COPDrelated disability. Pneumologie. 2009;63(3):136-143.

10. Perez T, Arnould B, Grosbois JM, et al. Validity, reliability, and responsiveness of a new short Visual Simplified Respiratory Questionnaire (VSRQ) for health-related quality of life assessment in chronic obstructive pulmonary disease. Int J Chron Obstruct Pulmon Dis. 2009;4:9-18.

11. Jones PW, Harding G, Berry P, Wiklund I, Chen WH, Kline LN. Development and first validation of the COPD Assessment Test. Eur Respir J. 2009;34(3):648-654.

12. Kocks JW, Kerstjens HA, Snijders SL, et al. Health status in routine clinical practice: validity of the clinical COPD questionnaire at the individual patient level. Health Qual Life Outcomes. 2010;8:135.

13. Stallberg B, Nokela M, Ehrs PO, Hjemdal P, Jonsson EW. Validation of the clinical COPD Questionnaire (CCQ) in primary care. Health Qual Life Outcomes. 2009;7:26.

14. Global Initiative for Chronic Obstructive Lung Disease: Global strategy for the diagnosis, management and prevention of chronic obstructive pulmonary disease. (Updated 2010). http://www.goldcopd.org/2010. Accessed December 8, 2010.

15. Charlson ME, Pompei P, Ales KL, Mackenzie CR. A new method of classifying prognostic comorbidity in longitudinal studies: development and validation. J Chronic Dis. 1987;40(5):373-383.

16. Jones PW, Quirk FH, Baveystock CM. The St. George's Respiratory Questionnaire. Respir Med. 1991;85 Suppl B:25-31.

17. Harwood RH, Rogers A, Dickinson E, Ebrahim S. Measuring handicap: the London Handicap Scale, a new outcome measure for chronic disease. Qual Health Care. 1994;3(1):11-16.

18. Mahler DA, Wells CK. Evaluation of clinical methods for rating dyspnea. Chest. 1988;93(3):580-586.

19. Sperber AD. Translation and validation of study instruments for cross-cultural research. Gastroenterology. 2004;126(1 Suppl 1): S124-S128.

20. Celli BR, Cote CG, Marin JM, et al. The body-mass index, airflow obstruction, dyspnea, and exercise capacity index in chronic obstructive pulmonary disease. $N$ Engl J Med. 2004;350(10):1005-1012.

21. Acquadro C, Conway K, Giroudet C, Mear I. Linguistic Validation Manual for Patient-Reported Outcomes (PRO) Instruments. Mapi Research Institute; 2004.

22. Ostini R, Nering ML. Polytomous Item Response Theory Models. Thousand Oaks, CA: Sage Publication, Inc.; 2006.

23. Hambleton RK, Swaminathan H, Rogers HJ. Fundamentals of Item Response Theory. Newbury Park CA: Sage Publications; 1991.

24. Hattie J. Methodology review: assessing unidimensionality of tests and items. Appl Psychol Meas. 1985;9:139-164.

25. Hays RD, Anderson R, Revicki D. Assessing reliability and validity of measurement in clinical trials. Quality of Life assessment in clinical trials: methods and practice. Oxford UK: Oxford University Press; 1998:169-182.

26. Turner RR, Quittner AL, Parasuraman BM, Kallich JD, Cleeland CS. Patient-reported outcomes: instrument development and selection issues. Value Health. 2007;10 Suppl 2:S86-S93.

27. Arnould B. Patient-reported outcomes and clinical practice. From measurement instruments to decision tools: much more than simple change in format. PRO Newsletter. 2006;36:21-24. 
28. World Health Organization (WHO): International Classification of Functioning, Disability and Health (ICF). http:/www.who/int/ classifications/icf/en/. Accessed April 13, 2011.

29. Kaptein AA, van Klink RC, de Kok F, et al. Sexuality in patients with asthma and COPD. Respir Med. 2008;102(2):198-204.

30. Nunnally JC, Bernstein IH. Psychometric theory. 3rd ed. New York: McGraw-Hill Inc; 1994.

31. Albuquerque AL, Nery LE, Villaca DS, et al. Inspiratory fraction and exercise impairment in COPD patients GOLD stages II-III. Eur Respir J. 2006;28(5):939-944.

32. Garcia-Rio F, Lores V, Mediano O, et al. Daily physical activity in patients with chronic obstructive pulmonary disease is mainly associated with dynamic hyperinflation. Am J Respir Crit Care Med. 2009;180(6): 506-512.
33. Feldman-Stewart D, Brundage MD. A conceptual framework for patient-provider communication: a tool in the PRO research tool box. Qual Life Res. 2009;18(1):109-114.

34. Cushing A, Metcalfe R. Optimizing medicines management: from compliance to concordance. Ther Clin Risk Manag. 2007;3(6): 1047-1058.

35. Lacasse Y, Brosseau L, Milne S, et al. Pulmonary rehabilitation for chronic obstructive pulmonary disease. Cochrane Database Syst Rev. 2002;(3):CD003793.

\section{Publish your work in this journal}

The International Journal of COPD is an international, peer-reviewed journal of therapeutics and pharmacology focusing on concise rapid reporting of clinical studies and reviews in COPD. Special focus is given to the pathophysiological processes underlying the disease, intervention programs, patient focused education, and self management protocols.

\section{Dovepress}

This journal is indexed on PubMed Central, MedLine and CAS. The manuscript management system is completely online and includes a very quick and fair peer-review system, which is all easy to use. Visit $\mathrm{http}: / / \mathrm{www}$.dovepress.com/testimonials.php to read real quotes from published authors.

Submit your manuscript here: http://www.dovepress.com/international-journal-of-copd-journal 